\title{
A NOTE ON THE KINSHIP SYSTEM OF KENYA LUO
}

\author{
William M. Christie, Jr. \\ University of Arizona
}

\section{Sümary}

The kinship terms of Kenya Luo show morphologically plural forms for both singular and plural possessors. This feature is not uniform throughout the system, but is present in some terms, absent in others, and variable in still others. This variability, together with the fact that similar patterns are not found in related or neighboring languages, suggests that the pattern is a residual inheritance in Luo.

\section{Possession in Luo}

Kenya Luo (central and south Nyanza Province, c. 2,000,000 speakers) has a system of pronominal possession distinguishing three persons and two numbers, with markers as follows (the normal Luo orthography, used here and by my principal informant, Mr. Odhiambo Orlale, does not distinguish tone or the hollow/ non-hollow vowel quality; but this is irrelevant to the present discussion):

$$
\begin{array}{ccc}
\text { sg. } & \text { p1. } \\
\text { 1. } & -a & -w a \\
\text { 2. } & -i & -u \\
\text { 3. } & -e & -g i
\end{array}
$$

These are attached to the possessed nouns in three ways:

(1) Some nouns, generally denoting intimately possessed objects or people (including most kinship terms), take these markers as direct suffixes, e.g. lak 'tooth', laka 'my tooth'.

(2) Some few nouns suffix these markers to a postposed mar (rarely mag ), e.g. mo 'grease', mo mara 'my grease'. This form is much more common with nominal possessors than with pronominal.

(3) The large majority of nouns insert an empty morph $-n-$ before the possessive suffix in the singular only, e.g. osiep 'friend', osiepna 'my friend', but osiepgi 'their friend'.

3. Possession and Kinship Terms

Kinship terms in Kenya Luo fall into six classes according to their patterns with the pronominal possessive suffixes:

(1) The first class, the largest, consists of those terms that have the 
same pattern of suffixes as do the non-kinship terms. Included in this class are wuod 'son', nyar 'daughter', chieg- 'wife', chuor 'husband', and (with an inserted $-n-$ ) mikeyini 'first wife'.
sg. $\quad \mathrm{p} 1$.
1. wuoda wuodwa
2. wuodi wuodu
3. wuode wuodgi

(2) The second class completely neutralizes number in the suffixes, with the morphologically plural forms being used. Included in this class are won 'father', min 'mother', owad- 'brother' or 'male cousin', and nyamin'sister' or 'female cousin'.

$$
\begin{aligned}
& \text { 1. wonwa } \\
& \text { 2. wonu } \\
& \text { 3. wongi }
\end{aligned}
$$

The remaining classes are mixtures of or variations on the patterns shown in the first two classes.

(3) In the third class there is neutralization of number only in the second and third persons, the first person being differentiated. This class contains only the words ner 'uncle' and wayo 'aunt'.

$$
\begin{aligned}
& \text { sg. p1. } \\
& \text { 1. nera nerwa } \\
& \text { 2. neru } \\
& \text { 3. nergi }
\end{aligned}
$$

(4) The fourth class has number neutralization in the second person only. This class contains only the noun maro 'stepmother (father's wife who is not one's biological mother)', which has other morphological irregularities.

$$
\begin{aligned}
& \text { sg. } \quad \mathrm{pl} \text {. } \\
& \text { 1. maara maar marwa or } \\
& \text { 3. maar mare or maaru margi or } \\
& \text { maro mare maro margi }
\end{aligned}
$$

(5) The fifth class has number neutralization throughout, save that the first person, when used in direct address, takes a singular suffix. This 
class contains only kwar 'grandfather' and da or dan 'grandmother'.

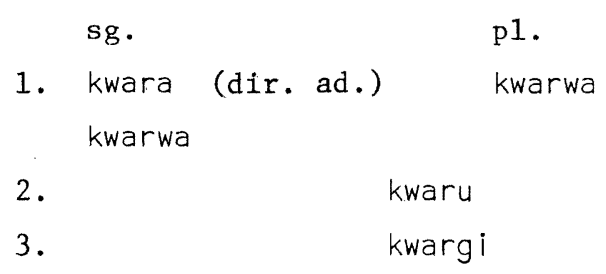

(6) The sixth class has the same alternation in the first person singular, while the second and third persons show number differentiation. This class contains only the noun nyakwar 'grandchild'.
sg.
p1.
1. nyakwara (dir. ad.) nyakwarwa
nyakwarwa
2. nyakwari
nyakwaru
3. nyakware
[nyakwargi ]

The form nyakwargi is recognized by native speakers, but it is not normally used if an alternative syntactic construction can be found that allows it to be avoided.

\section{Discussion}

It will be observed that, except for the irregular noun maro, when one finds one of the persons differing from the pattern seen in the other persons, it is the first person that is different. It will be observed also that if any person has number differentiation, the first person will have it. It may finally be observed that, except for ner and wayo, if there is differentiation in the first person and neutralization somewhere else, the differentiation in the first person is correlated with direct address. These observations allow one to posit an historically underlying pattern of number neutralization for the kinship terms. This pattern, however, has been subjected to two pressures to alter it. First is the pressure to make the morphology conform to performance in the first person singular. Second is the pressure to make the morphology conform to the pattern found in the other nouns in the language. One can then understand the histories of the classes in the following way.

In class 1, pressure for conformity to the pattern of other nouns has completely worked through, and the pattern is fully regularized. In class 2 , neither pressure has had any effect. One may well ask why these forms have escaped completely. The answer is that these forms are never used in direct address. Father and mother are addressed as baba and mama, while siblings are addressed by their first names only.

Skipping to class 5, we find that the pressure of direct address has given 
rise to an alternation in the first person singular. Otherwise the neutralization has remained. The alternation has become full differentiation in class 3 , and this same pressure was coupled with the general pressure for regularization in class 4 . Here only the second person retains the neutralization. Finally, the alternation in the first person singular appears to have spread by analogy to class 6 , which otherwise has been completely regularized.

I regard this number neutralization as an archaism in Kenya Luo. Such an analysis makes this an example of the familiar "colonial lag" in a language that has become geographically detached from the main body of West Nilotic languages, according to oral tradition, through migration of the Luo people from an area to the north. It is worth considering, however, whether this might be a Luo innovation. Several reasons suggest that it probably is not. In the first place, it is not at all usual to find innovations as striking as this would be unless either one sees in the main body of these languages some evidence of a start in this direction, or one sees a model for the change within the language itself or in a language with which it has come in contact. None of these conditions obtains. The other West Nilotic languages, including the closely related Lango-Acholi group, show no evidence of this pattern whatever. Nor is there any potential model in the neighboring languages, including the immediately adjacent Kisii or the all-pervasive Swahili. Nor, finally, is there any similar or related structure within luo that could provide any impetus for such an innovation. Given these facts, all evidence points to the probability that number neutralization in the kinship terms is a slowly disappearing archaism that is still partly retained only in Kenya Luo. 